\title{
Congenital duodenal web: successful management with endoscopic dilatation
}

Authors

Institution
Ujjal Poddar, Vikas Jain, Surender Kumar Yachha, Anshu Srivastava

Department of Pediatric Gastroenterology, Sanjay Gandhi Postgraduate Institute of Medical Sciences, Lucknow, India submitted 8. October 2016 accepted after revision 7. December 2015

\section{Bibliography}

Dol http://dx.doi.org/

10.1055/s-0041-110955

Published online: 19.1.2016

Endoscopy International Open 2016; 04: E238-E241

(c) Georg Thieme Verlag KG Stuttgart · New York

E-ISSN 2196-9736

Corresponding author: Ujjal Poddar, MD, DNB, DM Department of Pediatric Gastroenterology

SGPGIMS, Lucknow-226014

India

Phone: +91-522-249-4418

Fax: +91-522-266-8017

ujjalpoddar@hotmail.com
Background and study aims: Congenital duodenal web (CDW) is an uncommon cause of duodenal obstruction and endoscopic balloon dilatation has been reported in just eight pediatric cases to date. Here we are reporting three cases of CDW managed successfully with balloon dilatation.

Cases and methods: In 2014 we diagnosed three cases of CDW on the basis of typical radiological and endoscopic findings. Endoscopic balloon dilatation was done under conscious sedation with a through-the-scope controlled radial expansion (CRE) balloon.

Results: All three children presented late (median age 8 [range $2-9$ ] years) with bilious vomiting,

\section{Introduction}

\section{$\nabla$}

Congenital duodenal obstruction is one of the most common congenital anomalies, accounting for almost half of cases of neonatal intestinal obstruction, its cause is either an intrinsic defect in the wall (atresia, stenosis, or diaphragm) or extrinsic compression due to malrotation, annular pancreas or preduodenal portal vein [1-3]. Among all causes of congenital duodenal obstruction, congenital duodenal web (CDW) or diaphragm is uncommon and the second part of the duodenum is the most common location (85\%$90 \%$ of cases), followed by the third and fourth parts of the duodenum [4]. Complete or intact diaphragm is basically a duodenal atresia and perforated or fenestrated diaphragm is a subtype of duodenal stenosis [5].

Before the mid-1980s, surgery was the treatment of choice for congenital duodenal obstruction. However, with advances in therapeutic endoscopy, endoscopic procedures have become the preferred mode of treatment because of their simplicity, safety and reduced recovery time. To date, there has been a paucity of data on endoscopic treatment of CDW in pediatric patients. Endoscopic balloon dilatation of CDW has been upper abdominal distension, and failure to thrive. One of them had associated Down syndrome and another had horseshoe kidney. In all cases, CDW was observed in the second part of the duodenum beyond the ampulla, causing partial duodenal obstruction. After repeated endoscopic dilatation ( $2-4$ sessions), all three patients became asymptomatic. None of the patients experienced complications after balloon dilatation.

Conclusions: Duodenal diaphragm should be suspected in patients with abdominal distension with bilious vomiting, even in relatively older children. Endoscopic balloon dilatation is a simple and effective method of treating this condition.

reported in just eight pediatric cases so-far [68]. Here we report our experience with successful endoscopic balloon dilatation in three children with congenital duodenal web.

\section{Patients and methods}

$\nabla$

In 2014 we diagnosed three cases of CDW on the basis of characteristics barium meal followthrough pictures and findings from upper gastrointestinal (UGI) endoscopy. The standard UGI scope (outer diameter $8.8 \mathrm{~mm}$, GIF-Q 180, Olympus, Japan) was used in all cases. All three patients were subjected to endoscopic balloon dilatation under conscious sedation with midazolam and ketamine. Informed consent was taken from a parent before each session of dilatation. A through-the-scope (TTS) controlled radial expansion balloon (CRE: Microvasive, Boston Scientific Corporation, Natick, MA, USA) was used and the starting size of the balloon was $8 \mathrm{~mm}$ for patients aged $<3$ years and $10 \mathrm{~mm}$ for patients aged $>3$ years. A balloon up to $18 \mathrm{~mm}$ was used for follow-up dilatation. After inflation with saline, the balloon was kept in position across the diaphragm for 3 minutes and the procedure was repeated ev- 
Table 1 Clinical details of patients.

\begin{tabular}{|c|c|c|c|c|c|c|}
\hline Patient & $\begin{array}{l}\text { Age (yrs)l } \\
\text { sex }\end{array}$ & $\begin{array}{l}\text { Age at onset } \\
\text { of symptoms }\end{array}$ & $\begin{array}{l}\text { Location of } \\
\text { membrane }\end{array}$ & Symptoms & $\begin{array}{l}\text { Weight and } \\
\text { height z-score }\end{array}$ & Associated condition \\
\hline 1 & $9 / M$ & 3 months & $\begin{array}{l}\text { Second part } \\
\text { duodenum } \\
\text { distal to ampulla } \\
\text { of Vater }\end{array}$ & $\begin{array}{l}\text { - Stale food and bilious vomiting } \\
\text { - Upper abdominal distension with } \\
\text { visible peristalsis and borborygmi } \\
\text { - Failure to thrive }\end{array}$ & $\begin{array}{l}-4.25 \text { and } \\
-6.73\end{array}$ & $\begin{array}{l}\text { Down syndrome, hiatal } \\
\text { hernia, GERD, peptic } \\
\text { esophageal stricture }\end{array}$ \\
\hline 2 & $8 / F$ & Birth & $\begin{array}{l}\text { Second part } \\
\text { duodenum } \\
\text { distal to ampulla } \\
\text { of Vater }\end{array}$ & $\begin{array}{l}\text { - Bilious-vomiting } \\
\text { - Upper abdominal distension, } \\
\text { borborygmi and pain abdomen } \\
\text { - Failure-to-thrive }\end{array}$ & $\begin{array}{l}-3.98 \text { and } \\
-2.72\end{array}$ & Horseshoe kidney \\
\hline 3 & $2 \mathrm{yr}, 3 \mathrm{mo} / \mathrm{F}$ & 6 months & $\begin{array}{l}\text { Second part } \\
\text { duodenum } \\
\text { distal to ampulla } \\
\text { of Vater }\end{array}$ & $\begin{array}{l}\text { - Upper abdominal distension (post- } \\
\text { prandial with visible peristalsis) } \\
\text { - Bilious-vomiting } \\
\text { - Constipation } \\
\text { - Failure-to-thrive }\end{array}$ & $\begin{array}{l}-2.25 \text { and } \\
-3.88\end{array}$ & - \\
\hline
\end{tabular}

Table 2 Outcome of endoscopic dilatation.

\begin{tabular}{|c|c|c|c|c|c|c|}
\hline & Size of balloon & $\begin{array}{l}\text { No. of } \\
\text { sessions }\end{array}$ & $\begin{array}{l}\text { Interval between } \\
\text { sessions }\end{array}$ & Complications & $\begin{array}{l}\text { Follow up after } \\
\text { last session }\end{array}$ & Clinical status \\
\hline Case 1 & 12,15 and $18 \mathrm{~mm}$ & 3 & 3 weekly & Nil & 7 months & No vomiting or distension, gained weight \\
\hline Case 2 & 10 and $12 \mathrm{~mm}$ & 2 & 3 weeks & Nil & 9 months & No vomiting, gained weight \\
\hline Case 3 & $8,12,15$, and $18 \mathrm{~mm}$ & 4 & 3 weekly & Nil & 6 months & Asymptomatic, gained weight \\
\hline
\end{tabular}

ery 3 weeks until a patient became asymptomatic. Patients were observed for complications for 6 hours post-dilatation. The initial dilatation session was performed on an inpatient basis and subsequent dilatations were done as outpatient procedures.

\section{Case Reports}

All three children presented late (median age 8 years [range, 29]) with bilious vomiting, upper abdominal distension, and failure to thrive. One of them had associated Down syndrome and another had a horseshoe kidney. The clinical details about the patents are listed in Table 1. The outcome of their endoscopic dilatation procedures is listed in Table2. The details of individual cases are as follows.

\section{Patient 1}

A 9-year-old boy presented with vomiting, abdominal distension, and failure to thrive that began at age of 3 months. He had a history of large-volume, projectile, bilious vomiting that occurred three to four times a week. He was born to a mother of advanced reproductive age. On examination, the child was emaciated $(\checkmark$ Table 1 ) and had phenotypic features of Down syndrome. His abdomen was grossly distended with visible peristalsis. Investigation revealed normal complete blood counts $(\mathrm{CBC})$ and thyroid profile. An abdominal (erect) X-ray showed a double bubble sign and barium meal follow-through ( $\$$ Fig. 1 a) revealed narrowing in the second part of the duodenum with dilated proximal duodenum and stomach. Abdominal ultrasonography did not show any evidence of annular pancreas. UGI endoscopy showed a passable narrowing at the lower end of the esophagus with circumferential ulcers (LA-D GERD) and hiatal hernia. There was a narrowing in the second part of the duodenum just distal to the ampulla, with a tiny hole at the center with proximal duodenal dilatation ( Fig.1 b). Endoscopic dilatation of duodenal web was done with a 10-mm CRE balloon under fluoroscopic guidance ( $\bullet$ Fig. 1 c). Following the dilatation, the endoscope could be negotiated easily beyond the narrowing. The distal duodenum was normal and narrowing was appreciated as a membrane (suggestive of duodenal web). Two more sessions of dilatation were done ( $\bullet$ Table 2). At the same time, the child was started on a proton pump inhibitor for reflux esophagitis and peptic stricture. On follow up, the child's vomiting and distension had subsided, he began gaining weight and his esophageal ulcer healed.

\section{Patient 2}

An 8-year-old girl presented with complaints of vomiting and failure to thrive since birth. She was having bilious vomiting two to three times per week with increased frequency of vomiting over the last 3 years. She also complained of pain and upper abdominal distension, which used to decrease after vomiting. On examination she had significant failure to thrive ( $\bullet$ Table 1 ) and her abdominal examination revealed epigastric distension. Investigations revealed normal $\mathrm{CBC}$, serum creatinine, and thyroid profile. Abdominal ultrasonography showed a horseshoe kidney and no evidence of annular pancreas. Her abdominal x-ray (erect) showed a double bubble sign and barium meal followthrough ( $\bullet$ Fig. $2 a$ ) revealed narrowing in the second part of the duodenum with a dilated proximal duodenum. UGI endoscopy showed dilation of the first and proximal second part of duodenum and narrowing with a tiny lumen in the second part of duodenum just distal to the papilla ( Fig. 2 b). Endoscopic dilatation of duodenal web was done with a 10-mm CRE balloon dilator $(\checkmark$ Fig. 2c) under fluoroscopic guidance and the post-dilation appearance was the same as in Patient 1 . After 3 weeks, dilatation was repeated with a 12-mm CRE balloon, after that child's vomiting subsided, her abdominal distension decreased, and she started gaining weight. 

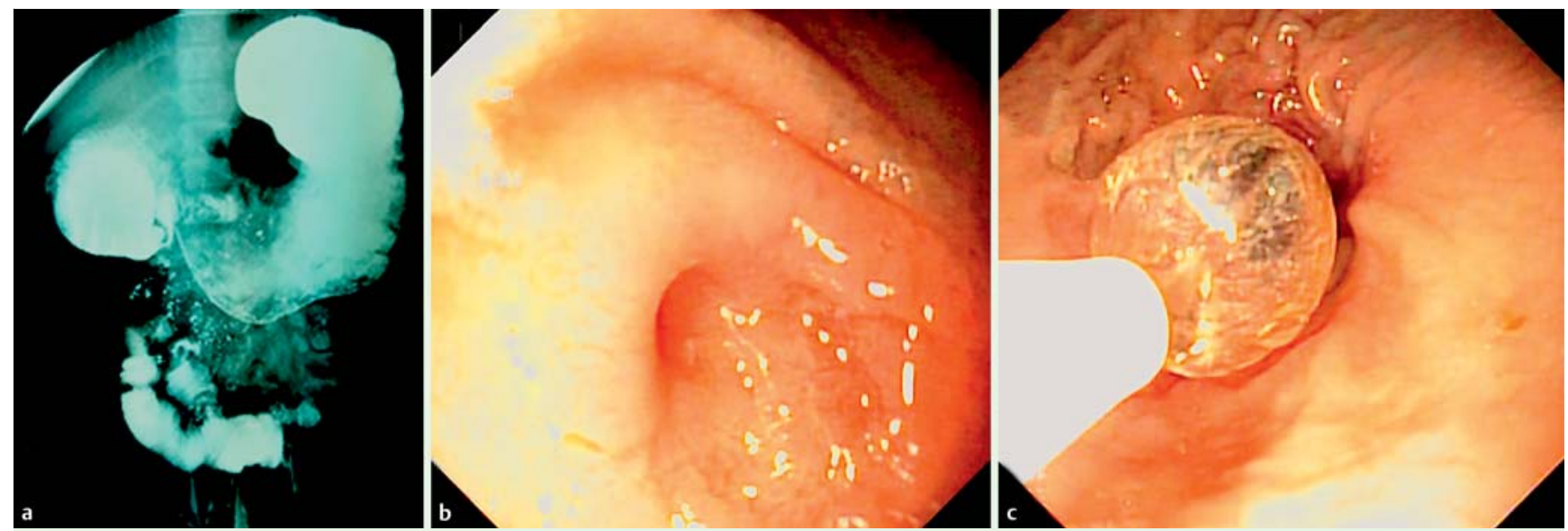

Fig. 1 a Barium meal follow-through in a 9-year-old boy showed grossly dilation of the first and proximal second parts of the duodenum due to a membrane. b Endoscopy revealed duodenal obstruction with a tiny lumen. $\mathbf{c}$ Endoscopy showing the balloon catheter in situ.
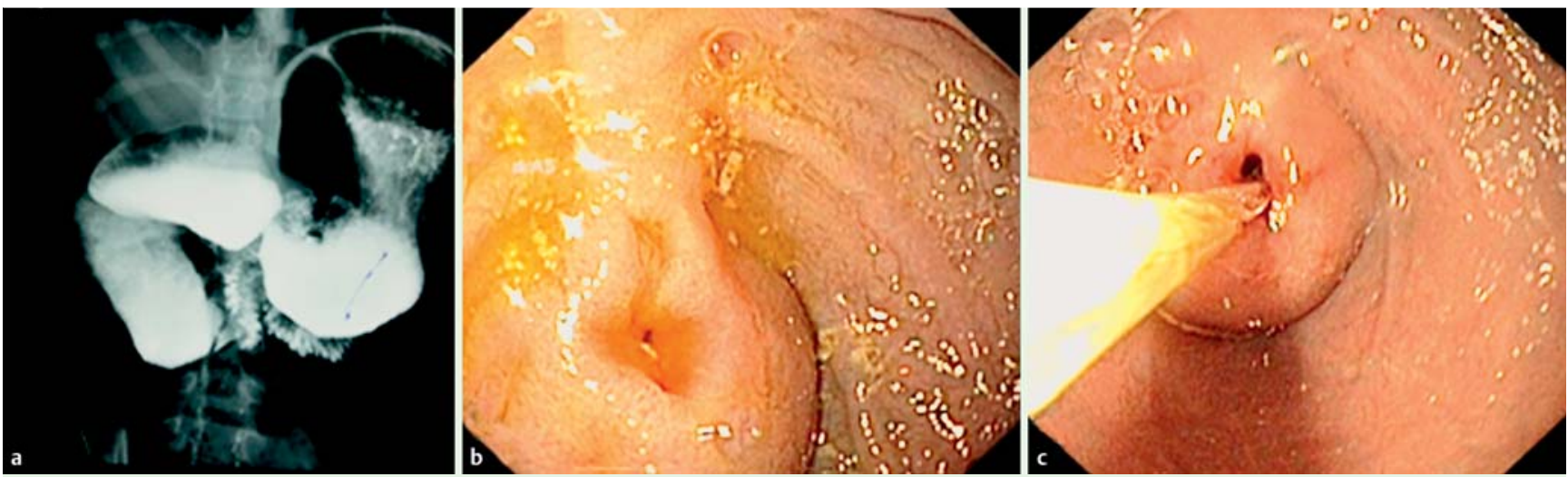

Fig.2 a Barium meal follow-through of an 8-year-old girl showing duodenal obstruction with grossly dilation of the first and second parts of duodenum. b Endoscopic image showing narrowing just distal to the ampulla with bulging (bellowing) of the membrane and a tiny lumen. $\mathbf{c} A$ balloon catheter passing through the lumen of diaphragm.

\section{Patient 3}

A 2-year-old girl presented with a history of vomiting, failure to thrive, and upper abdominal distension for 6 months. She was having bilious vomiting once or twice a week. On examination the patient had wasting, stunting ( $\bullet$ Table 1 ), and her abdominal examination revealed epigastric distension. Investigations revealed normal $\mathrm{CBC}$ and thyroid profile. Barium meal followthrough ( Fig. 3 a) showed narrowing in the second part of the duodenum with a dilated proximal duodenum. Abdominal ultrasonography did not show any evidence of annular pancreas. UGI endoscopy showed a membrane-like obstruction with a tiny opening in the second part just distal to the papilla (the membrane was bellowing into the proximal dilated duodenum [wind-sock] due to reverse peristalsis, a characteristic picture of duodenal diaphragm) ( $\bullet$ Fig.3 b). Endoscopic dilatation of duodenal web was started with an 8-mm CRE balloon ( $\bullet$ Fig.3c). Three more dilatation were performed at 3-week intervals ( $\bullet$ Table 2), using progressively larger balloons, after which the child's vomiting subsided, her abdominal distension decreased, she started gaining weight.

\section{Discussion}

$\nabla$

Congenital duodenal web is a rare condition that usually presents early in life. Patients with complete-type duodenal web present early in the neonatal period with duodenal obstruction whereas the fenestrated type may present late. Reports also exist of congenital duodenal web diagnosed in adulthood [5, 9]. In our case series, all three patients presented late as they had the fenestrated type of web with recurrent bilious vomiting, abdominal distension, and failure to thrive. All three children had a web in the second part of the duodenum (distal to the ampulla), which is the most common site of CDW formation [4]. Multiple associated disorders like Down syndrome, cardiac anomalies, malrotation of the gut, vertebral defect, renal anomalies etc. have been described with CDW [10]. In our series one child had associated Down syndrome and another one had a horseshoe kidney.

Surgery, in the form of excision and duodenoplasty or bypass procedures like duodeno-duodenostomy and dudeno-jejunostomy used to be the conventional modality for treatment of CDW $[2,3]$. However, with the advent of endoscopic procedures for various gastrointestinal conditions, treatment with procedures such as endoscopic membranotomy with laser [11], sphincterotome [12], high-frequency-wave snare/cutter [12], hot biopsy forceps [4], insulated-tip diathermic knife [13] and needle knife [14] have been reported. Endoscopic therapy has become popular because it produces no abdominal incision (scar), is not asso- 

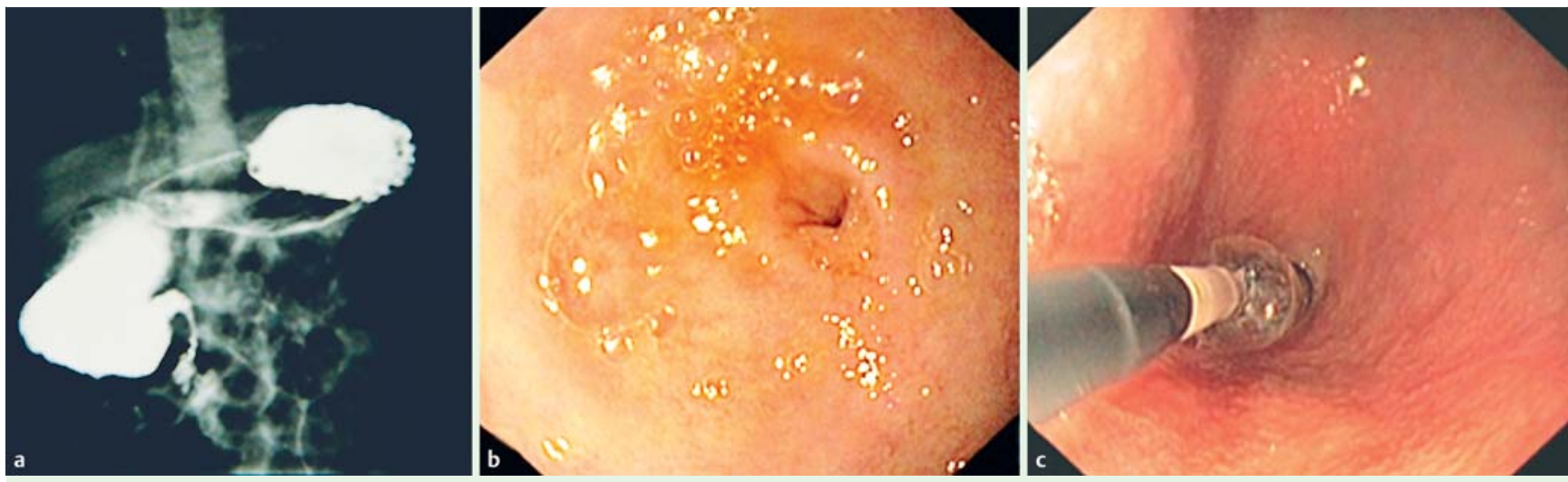

Fig.3 a Barium meal follow-through of a girl aged 2 years and 3 months demonstrating duodenal obstruction with grossly dilation of the first and proximal second parts of the duodenum. $\mathbf{b}$ Endoscopic image showing the duodenal diaphragm with a tiny central lumen. $\mathbf{c}$ Endoscopic image showing roomy duodenal lumen proximal to the obstruction and the balloon catheter in situ.

ciated with complications such as adhesion development, involves shorter hospital stay, and the procedures sometimes can be performed without general anaesthesia. More invasive endoscopic procedures such as cutting the web with an electrocautery device or laser carry risks of perforation, excessive bleeding and trauma to the ampulla of Vater. Endoscopic dilatation, in contrast, is a relatively safe procedure with a reduced risk of the previously mentioned complications. Endoscopic balloon dilatation produces tearing in the membrane of the diaphragm, which contains only mucosa and submucosa and lacks a muscular layer.

The first endoscopic balloon dilatation of CDW, done with a 12$\mathrm{mm}$ balloon catheter was reported by Asabe et al [6] in 2008 in a 9-day-old boy. The dilatation was repeated at 30 and 51 days of life with 13-mm and 13.5-mm balloon catheters. Mochizuki et al [7] reported another case of 7-month-old girl and, like us, they used a through-the-scope CRE balloons measuring $10 \mathrm{~mm}$, $12 \mathrm{~mm}$, and $15 \mathrm{~mm}$ for proximal jejunal web. Recently, Huang et al [8] reported their experience with endoscopic balloon dilatation in a series of six cases involving children aged 2 to 37 months with CDW. They used $10-\mathrm{mm}$ to $16-\mathrm{mm}$ balloon catheters and with the exception of one child, all were treated only with balloon dilatation. One child required endoscopic electrocauterization of an obstructing membrane following balloon dilatation. In our series, we managed to treat all three patients with endoscopic balloon dilatation only. All of our patients became asymptomatic after two to four sessions of endoscopic dilatation and none developed any complications.

In conclusion, duodenal diaphragm should be suspected in cases of abdominal distension with bilious vomiting in children, even those who are relatively older. Endoscopy usually confirms the diagnosis. Endoscopic balloon dilation is a simple and effective method of treating this condition.

\section{References}

1 Lawrence MJ, Ford WD, Furness ME et al. Congenital duodenal obstruction: early antenatal ultrasound diagnosis. Pediatr Surg Int 2000; 16: $342-345$

2 Bailey PV, Tracy TF Jr., Connors RH et al. Congenital duodenal obstruction: a 32-year review. J Pediatr Surg 1993; 28: 92-95

3 Mustafawi AR, Hassan ME. Congenital duodenal obstruction in children: a decade's experience. Eur J Pediatr Surg 2008; 18: 93 -97

4 Beeks A, Gosche J, Giles H et al. Endoscopic dilatation and partial resection of a duodenal web in an infant. J Pediatr Gastroenterol Nutr 2009; 48: $378-381$

5 Grosfeld JL, Roscorla FJ. Duodenal atresia and stenosis: Reassessment of treatment and outcome based on antenatal diagnosis, pathologic variance and long term follow up. World J Surg 1993; 17: 301 - 309

6 Asabe K, Oka Y, Hoshino $S$ et al. Modification of endoscopic management of congenital duodenal stenosis. Turk J Peidiatr 2008; 50: 182 185

7 Mochizuki K, Obatake M, Kosaka T et al. Endoscopic balloon dilatation for congenital membrane stenosis in the jejunum in an infant. Pediatr Surg Int 2011; 27: 91 -93

8 Huang $M H$, Bian $H Q$ Liang $C$ et al. Gastroscopic treatment of membranous duodenal stenosis in infants and children: report of 6 cases. J Pediatr Surg 2015; 50: 413-416

9 Norman CH Jr, Pacis AB. Congenital Duodenal Web in an Adult. J Natl Med Assoc 1978: 70; 797-798

10 Sarin $Y K$, Sharma A, Sinha $S$ et al. Duodenal webs: an experience with 18 patients. J Neonatal Surg 2012; 1: 20

11 Kay GA, Lobe TE, Custer MD et al. Endoscopic laser ablation of congenital duodenal webs in the newborn: a case report of limited success with criteria for patient selection. J Pediatr Surg 1992; 27: 279-281

12 Torroni F, De Angelis P, Caldaro T et al. Endoscopic membranectomy of duodenal diaphragm: pediatric experience. Gastrointest Endosc 2006; 63: $530-531$

13 Barabino A, Gandullia P, Arrigo $S$ et al. Successful endoscopic treatment of a double duodenal web in an infant. Gastrointest Endosc 2011; 73: 401-403

14 DiMaio CJ, Kamal N, Hogan CM et al. Pediatric therapeutic endoscopy: endoscopic management of a congenital duodenal web. Gastrointest Endosc 2014; 80: $166-167$

Competing interests: None 